\title{
Effect of Retrogression and Reaging on Stress Corrosion Cracking of Spray Formed Al Alloy*
}

\author{
Ruiming Su, Yingdong Qu, Xiang Li, Junhua You, Rongde Li \\ School of Materials Science and Engineering, Shenyang University of Technology, Shenyang, China \\ Email: quyingdong@163.com
}

Received 19 November 2015; accepted 25 January 2016; published 28 January 2016

Copyright (C) 2016 by authors and Scientific Research Publishing Inc.

This work is licensed under the Creative Commons Attribution International License (CC BY). http://creativecommons.org/licenses/by/4.0/

(c) (i) Open Access

\begin{abstract}
Stress corrosion cracking (SCC) resistance of a spray formed Al-Zn-Mg-Cu alloy underwent retrogression and reaging (RRA) was studied by slow strain rate tests in dry air and $3.5 \mathrm{wt} \% \mathrm{NaCl}$ solution. The results showed that after RRA treatment, interrupted $\eta$ phases at grain boundaries and slightly wide precipitate free zones could decrease SCC susceptibility of the alloy. Lots of reticular dislocations appeared in deformation process could prevent hydrogen induced cracking, and then SCC. Abundance transgranular dispersive $\eta$ ' phases separated out again promoted tensile strength to 759.4 MPa. The fracture ways of the specimens were dimple fracture in dry air and sub-cleavage fracture in $3.5 \% \mathrm{NaCl}$ solution.
\end{abstract}

\section{Keywords}

Spray Forming, Al-Zn-Mg-Cu Alloy, Retrogression and Reaging, Stress Corrosion Cracking

\section{Introduction}

Al-Zn-Mg-Cu alloys are precipitation hardening alloys, with a vast number of applications in the aerospace industry [1] [2]. Because of limitation on traditional casting process, the strength of the alloys hardly surpasses $700 \mathrm{MPa}$ [3] [4]. Until spray forming has been used on the alloys, the strengths are elevated to over $750 \mathrm{MPa}$ [5] [6].

Such as structural material, it is not only considered the strength and toughness, but also focused on stress corrosion cracking (SCC) resistance [7]-[10]. In regard to the SCC mechanisms on Al-Zn-Mg-Cu alloys, there

\footnotetext{
*This research was financially supported by the National Natural Science Foundation of China (51574167) and Program for Innovative Research Team in University of Liaoning Province (LT2015020).
}

How to cite this paper: Su, R.M., Qu, Y.D., Li, X., You, J.H. and Li, R.D. (2016) Effect of Retrogression and Reaging on Stress Corrosion Cracking of Spray Formed Al Alloy. Materials Sciences and Applications, 7, 1-7. 
are anodic dissolution theory [11], hydrogen induced cracking (HIC) theory [12] and "Mg-H" theory [13] [14]. For these studies and theories, there are some reports of heat treatment on SCC resistance of Al-Zn-Mg-Cu alloy [15]-[17]. Especially, the effects of retrogression and reaging (RRA) treatment on SCC resistance are completely remarkable [18] [19]. But the alloys are prepared with traditional casting process in above-mentioned reports. Some papers [20]-[23] report the effect of aging treatment on spray formed alloy, but the SCC resistance is not involved.

Some differences on microstructure of alloy (e.g. solid solubility or grain size) between spray forming and traditional casting have been proved by results [24]-[26]. Those differences also influence SCC resistance after RRA treatment and the regularity need to study.

To offer a data for optimizing aging treatments on spray forms Al-Zn-Mg-Cu alloy and reference for next step research, this paper studies of RRA treatment on microstructure and SCC resistance of spray form 7075 alloy with scanning electron microscope (SEM), transmission electron microscope (TEM) and slow strain rate tests, compared with T6 and T73 treatments, and discuss results.

\section{Experimental}

The 7075 aluminum alloy with alloying elements of $5.48 \mathrm{wt} \% \mathrm{Zn}, 2.21 \mathrm{wt} \% \mathrm{Mg}, 1.48 \mathrm{wt} \% \mathrm{Cu}, 0.189 \mathrm{wt} \% \mathrm{Cr}$, $0.371 \mathrm{wt} \% \mathrm{Fe}$ and $0.121 \mathrm{wt} . \% \mathrm{Si}$ was sprayed with atomization gas of nitrogen $\left(\mathrm{N}_{2}\right)$, spray distance of $370 \sim 380$ $\mathrm{mm}$, substrate eccentricity of $60 \sim 65 \mathrm{~mm}$, conduit bore of $3.6 \mathrm{~mm}$, incidence angle of $37^{\circ} \sim 39^{\circ}$, spray temperature of $770^{\circ} \mathrm{C} \sim 780^{\circ} \mathrm{C}$, crucible temperature of $735^{\circ} \mathrm{C} \sim 745^{\circ} \mathrm{C}$, horizontal velocity of $0.15 \mathrm{~mm} / \mathrm{s}$, and vertical velocity of $0.18 \mathrm{~mm} / \mathrm{s}$. Then resulting bar was extruded at temperature of $400^{\circ} \mathrm{C}$, ratios of 30:1 and feeding rate of $1.5 \mathrm{~mm} / \mathrm{s}$.

The test samples were cut from the as-extruded bar for the two-stage solid solution, i.e., $450^{\circ} \mathrm{C}$ for $1 \mathrm{~h}$ and $475^{\circ} \mathrm{C}$ for $2 \mathrm{hrs}$, respectively, after which the samples were water quenched to room temperature. Samples were aged at $120^{\circ} \mathrm{C}$ for $24 \mathrm{hrs}$ as $\mathrm{T} 6$ treatment, retrogressed at $200^{\circ} \mathrm{C}$ for $10 \mathrm{~min}$ and re-aged at $120^{\circ} \mathrm{C}$ for $24 \mathrm{hrs}$ (RRA). In addition, others samples were aged as T73 treatment (at $120^{\circ} \mathrm{C}$ for 8 hrs and $160^{\circ} \mathrm{C}$ for $16 \mathrm{hrs}$ ) for comparison.

Slow strain rate tested by SCC-1 stress corrosion experimental system refer to international standard ISO 7539 - 7:2005, specimen sizes are shown as Figure 1, strain rate was $10^{-6} \mathrm{~s}^{-1}$ in dry air or $3.5 \mathrm{wt} \% \mathrm{NaCl}$ solution at $35^{\circ} \mathrm{C} \pm 1{ }^{\circ} \mathrm{C}$ until cracking. Appearances of fracture were observed with S-3400 N scanning electron microscope, operating at $15 \mathrm{kV}$. The $3 \mathrm{~mm}$ diameter disks for TEM observation were punched out directly from samples which were mechanically ground down to $60 \mu \mathrm{m}$ thickness after aging. These disks were electropolished using a DJ-2000 twin-jet electropolisher with a $30 \%$ nitric acid solution in methanol at $-30^{\circ} \mathrm{C}$. TEM examinations were performed using a JEM-2100 transmission electron microscope.

\section{Results}

To judge the SCC resistance, stress corrosion index $I_{\text {SSRT }}$ was defined by processing various mechanical properties with slow strain rate test.

$$
I_{\mathrm{SRRT}}=1-\frac{\sigma_{\mathrm{NaCl}} \times\left(1+\delta_{\mathrm{NaCl}}\right)}{\sigma_{\mathrm{air}} \times\left(1+\delta_{\mathrm{air}}\right)} .
$$

where, $\delta_{\mathrm{NaCl}}$ is elongation in $3.5 \mathrm{wt} \% \mathrm{NaCl}$ solution (\%), $\delta_{\text {air }}$ is elongation in dry air (\%), $\sigma_{\mathrm{NaCl}}$ is tensile strength in $3.5 \mathrm{wt} \% \mathrm{NaCl}$ solution (MPa), $\sigma_{\text {air }}$ is tensile strength in dry air (MPa). The SCC resistance increases with the $I_{\text {SSRT }}$ close to 0 . The slow strain rate test properties of spray formed 7075 alloy after various aging treatments are listed in Table 1.

From Table 1, it can be seen that there are some differences on three aging treatments in dry air. After T6 treatment, strength maintains at a high level, the tensile strength of the alloy is $777.2 \mathrm{MPa}$, but the elongation is

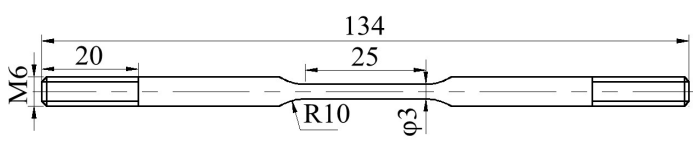

Figure 1. Sizes of the specimens for slow strain rate tests (mm). 
Table 1. Properties of the alloy after various aging treatments with slow strain rate tests.

\begin{tabular}{|c|c|c|c|c|c|}
\hline \multirow{2}{*}{ Aging treatment } & \multicolumn{2}{|c|}{$\sigma_{b} / \mathrm{MPa}$} & \multicolumn{2}{|c|}{$\delta / \%$} & \multirow{2}{*}{$I_{\mathrm{SSRT}}$} \\
\hline & air & $\mathrm{NaCl}$ & air & $\mathrm{NaCl}$ & \\
\hline T6 & 777.2 & 642.1 & 6.24 & 4.22 & 0.404 \\
\hline T73 & 676.5 & 660.8 & 8.48 & 7.95 & 0.078 \\
\hline RRA & 759.4 & 729.5 & 8.36 & 7.51 & 0.125 \\
\hline
\end{tabular}

only 6.24\%. After T73 treatment, the elongation rises to $8.48 \%$, but the tensile strength of the alloy is only 676.5 MPa which reduced 13\% than T6. The contradiction on tensile strength and elongation between T6 and T73 treatments was remitted by RRA treatment. The tensile strength of the alloy is $759.4 \mathrm{MPa}$ which is closed to T6, the elongation is $8.36 \%$ which is near to T73.

The slow strain rate test results in $3.5 \% \mathrm{NaCl}$ solution are also different. The elongation of the specimen after $\mathrm{T} 6$ treatment is $4.22 \%$ which is the least among three aging treatments and the tensile strength lost seriously remains 642.1 MPa. After T73 treatment, the tensile strength and elongation of specimens have few lost. The limitation of T73 treatment by which the tensile strength is lower in dry air, so the tensile strength is only 660.8 MPa which is a little more than $\mathrm{T} 6$ in corrosive medium ( $\mathrm{NaCl}$ solution). The tensile strength and elongation of alloy after RRA treatment also lose rarely. Because the tensile strength is higher in dry air, the tensile strength is 729.5 MPa which outclass T6 and T73 treatments in corrosive medium. And the elongation is $7.51 \%$ closed T73 level.

In stress corrosion index, the $I_{\mathrm{SSRT}}$ of the specimen after $\mathrm{T} 6$ treatment is biggest one. The index expresses that the SCC resistance maintain at a low level. Comparing with in dry air, both the tensile strength and elongation of specimens are significantly reduced in $3.5 \% \mathrm{NaCl}$ solution. The $I_{\text {SSRT }}$ with $\mathrm{T} 73$ treatment reflect the wonderful SCC resistance. Comparing with in dry air, the losses of tensile strength and elongation are only $2.32 \%$ and $6.25 \%$ respectively in $3.5 \% \mathrm{NaCl}$ solution. After RRA treatment, the spray formed 7075 alloy has outstanding tensile properties in dry air by slow strain rate test, the tensile strength is closed to T6 and elongation is near to T73. It can be found that the SCC resistance is little inferior to T73 in $3.5 \% \mathrm{NaCl}$ solution by slow strain rate test. And the tensile strength and elongation of the alloy are $729.5 \mathrm{MPa}$ and $7.51 \%$ respectively. Combination properties of the spray formed 7075 alloy after RRA treatment are excellent.

Fracture surfaces of slow strain rate test in dry air and 3.5\% $\mathrm{NaCl}$ solution after RRA treatments are shown as Figure 2. From Figure 2(a), it can be seen that tensile fracture of specimen after RRA treatments in dry air is dimple fracture, dimples are small and uniformity, and dimple diameter is almost $2 \mu \mathrm{m}$. In $3.5 \% \mathrm{NaCl}$ solution, Figure 2(b), the fracture is similar to cleavage fracture but on typical river or ligule patterns, and there are some tear ridges on surface of fracture, so this fracture can be classified as quasi-cleavage fracture.

Figure 3 shows TEM images of spray formed 7075 alloy after T6, T73 and RRA treatments. From Figure $3(\mathrm{a})$, it can be seen that abundance transgranular $\eta^{\prime}$ phases are thin, isolated and dispersed after T6 treatment. Sizes of the $\eta^{\prime}$ phases are $1 \sim 2 \mathrm{~nm}$. At grain boundaries, $\eta$ phases are continuous and precipitate free zones (PFZ) are about $5 \mathrm{~nm}$. From Figure 3(b), it can be found that the transgranular $\eta^{\prime}$ phases after T73 treatment are bigger and more agminate than them after T6 treatment. Volume fraction of $\eta^{\prime}$ phases depressed and sizes of the $\eta^{\prime}$ phases are $3 \sim 5 \mathrm{~nm}$. At grain boundaries, $\eta$ phases interrupt and PFZ widen to $25 \mathrm{~nm}$. From TEM image after RRA, as Figure 3(c), it can be found that the tiny dispersive homogeneous $\eta^{\prime}$ phases were separated out again in grains. At this moment, the main strengthening phases were $\eta^{\prime}$ and $\eta$. And precipitated phases on grain boundaries were thick and discontinuous $\eta$ phases. Those interrupted $\eta$ phases at grain boundaries are analogous to them after T73 treatment.

\section{Discussion}

The usual precipitation sequence of 7xxx series aluminum alloys can be summarized as [27]: SSSS (Super-saturated solid solution) $\rightarrow$ GP zones $\rightarrow$ metastable $\eta^{\prime} \rightarrow$ stable $\eta$. GP zones are metastable, coherent solute clusters of $\mathrm{Zn}, \mathrm{Mg}$ and $\mathrm{Cu}$. The metastable $\eta$ ' phases, $\mathrm{Al}, \mathrm{Cu}$ and $\mathrm{Mg}$ components base on a solid solution of $\mathrm{MgZn}_{2}, \mathrm{Mg}(\mathrm{ZnCuAl})_{2}$ or $\mathrm{Mg}\left(\mathrm{Zn}_{2}, \mathrm{AlMg}\right)$ appear as discrete platelet particles that are semi-coherent with the matrix, which is known to populate within the grains, and $\eta$ is pseudostable, non-coherent of the same phase 


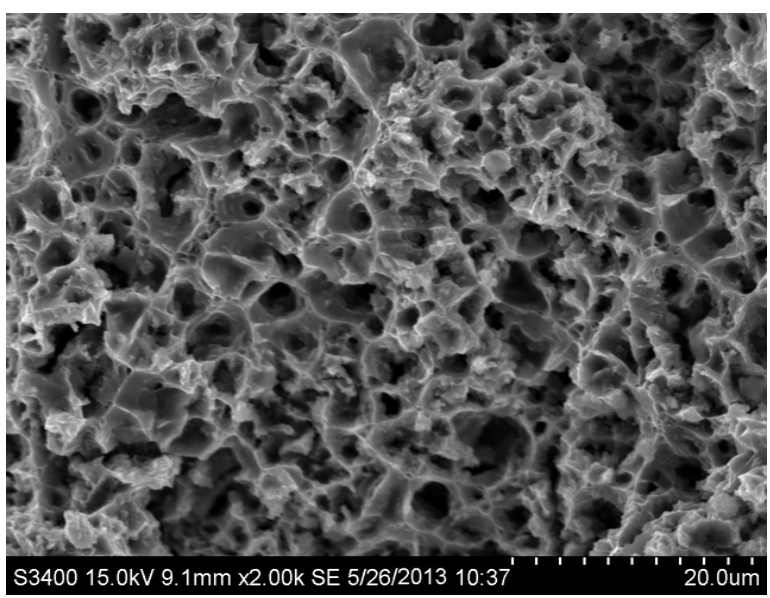

(a)

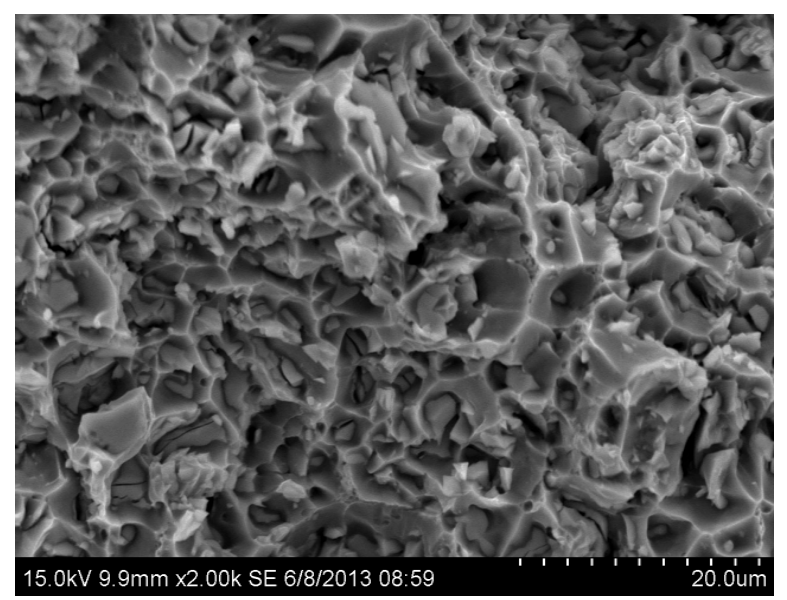

(b)

Figure 2. Fracture surfaces of slow strain rate test in different environment after RRA treatments: (a) in dry air (b) in 3.5\% $\mathrm{NaCl}$ solution.

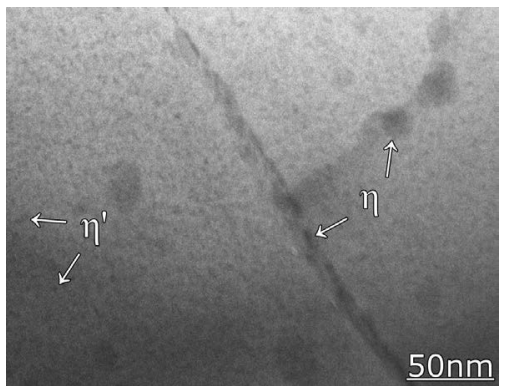

(a)

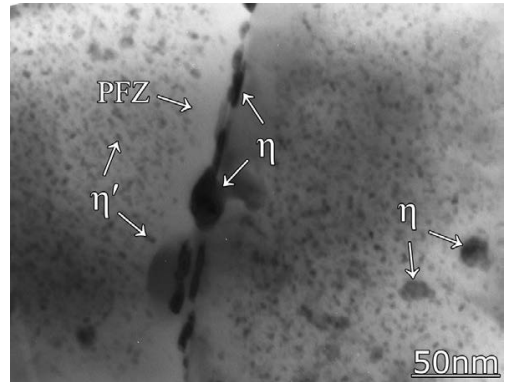

(b)

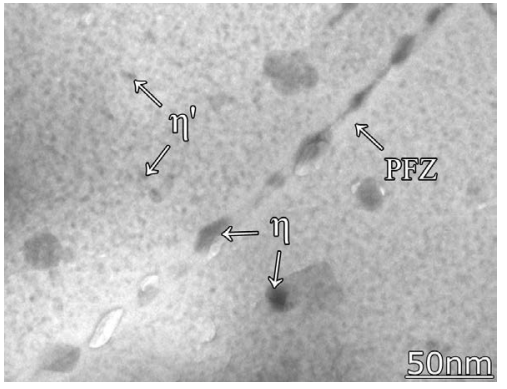

(c)

Figure 3. TEM images of alloy after various aging treatments: (a) T6, (b) T73, (c) RRA.

appearing as rods or plates, which is known to populate the grain boundary. Strengths of the alloy are immediately influenced by sizes and volume fraction of strengthening phases.

The strength of the alloy mainly relies on matrix precipitates (MPt) during the whole aging process, the strength of the alloy changes with characteristics of GP zone, $\eta^{\prime}$ and $\eta$. The best strength depends on fine homogeneously dispersive MPt. Plasticity, toughness and corrosion resistance of the alloy are remarkably influenced by structure and chemical property of grain boundary precipitates (GBP). There is a popular belief that continuous GBP is harmful to properties of the alloy. Because relative movement of crystalline grains in deformation process has been impeded by continuous GBP, plasticity and toughness of the alloy are completely injured. On the other hand, the continuous GBP is preferentially dissolved as anodes in anodic dissolution. Because the potential of GBP, PFZ and matrix is $-1.05 \mathrm{~V},-0.85 \mathrm{~V}$ and $-0.75 \mathrm{~V}$ respectively, the potential difference (PD) between GBP and precipitate free zones (PFZ) is less than the PD between GBP and matrix. With regard to corrosion resistance of the alloy, widening PFZ can remit the corrosion sensibility and improve corrosion resistance of alloy.

And slow strain rate test was an accelerated SCC process which is stable and placid. This method can verify whether material have SCC susceptibility or not in a short time. According to the slow strain rate tests, crystalline grains slip deformation and some dislocations left.

After T6 treatment, abundance tiny transgranular $\eta^{\prime}$ phases keep the tensile strength at 777.2 MPa. And because the $\eta$ phases at grain boundaries are preferentially dissolved as anodes, the galvanic corrosions formed by aluminum matrix and continuous $\eta$ phases lead to bad SCC susceptibility of the alloy after T6 treatment.

After T73 treatment, the transgranular $\eta^{\prime}$ phases grow up and volume fraction of $\eta^{\prime}$ phases depressed, so the tensile strengths of the alloy is only $676.5 \mathrm{MPa}$. But, after T73 treatment, interrupted $\eta$ phases can constitute an obstacle to forming the galvanic corrosions and improve SCC resistance of the alloy. 
From TEM of alloy after RRA, as Figure 3(c), it can be found that the tiny dispersive homogeneous $\eta^{\prime}$ phases were separated out again in grains. At this moment, the main strengthening phases were $\eta^{\prime}$ and $\eta$. After RRA, it is the reason of high strength that $\eta^{\prime}$ phases were separated out by alloying elements into which lots of GP zones and $\eta^{\prime}$ smaller than critical dimension were dissolved at retrogression treatment. And precipitated phases on grain boundaries were thick and discontinuous $\eta$ phases. Those interrupted $\eta$ phases at grain boundaries are analogous to them after T73 treatment and can constitute an obstacle to forming the galvanic corrosions and improve SCC resistance of the alloy. After RRA treatment, the alloy both has high strength and favorable SCC resistance.

The effects of PFZ still have different opinions in academia. But, as the result of this experiment, wide PFZ can improve plasticity and SCC resistance of alloy. This result fits Jiang's conclusion [28] [29].

Apart from the above, Wei [30] affirms that hydrogen atoms released by hydration surface which has been formed with hydrones $\left(\mathrm{H}_{2} \mathrm{O}\right)$ and fresh aluminum alloys infiltrate plastic zone of crack tip via diffusion after studying on fatigue crack growth of aluminum alloys. Those hydrogen atoms can speed crack growth up. For the Al-Zn-Mg-Cu alloys, hydrogen atoms can be released at cathode when anodic dissolution. Such hydrogen atoms are even few, but they influence crack formation and growth, even crack growth by anodic dissolution, to a certain extent.

SCC resistance is also influenced by dislocations in material. Hydrogen atoms form atmospheres around dislocations, and those hydrogen atmospheres move with dislocations together. Chu [31] reported that the cleavage crack nuclei could be founded by dislocation reaction of moving dislocations with hydrogen atmospheres, by which hydrogen was stayed in crack nuclei. All the phenomena above mentioned cause hydrogen embrittlement of material. For the alloy after T6 treatment, relationship between dislocation and SCC resistance can be explained by above views. But there are interlaced tangled reticular dislocations in the matrix of spray formed 7075 aluminum alloy after RRA treatment during slow strain rate test, as Figure 4. Reticular dislocations which have bad mobility are unusual in tradition casting Al-Zn-Mg-Cu alloys. Strengthening phases (the black blocks) separated out in these reticular dislocations can pin them, so the possibility of hydrogen embrittlement caused by above-mentioned moving dislocations sharply fall down. In macroscopic view, it is shown that fractures of specimens after RRA treatment by slow strain rate test are dimple fracture in dry air and quasi-cleavage fracture in 3.5\% $\mathrm{NaCl}$ solution, as in Figure 2. So, it can be consider that reticular dislocations are the traps for hydrogen in a qualified sence, whether in HIC or "Mg-H" theory, conducive to improving SCC resistance of alloys.

\section{Conclusions}

After retrogression and reaging (RRA) treatment, abundance tiny transgranular $\eta^{\prime}$ phases separated out again maintain the tensile strength of the spray formed 7075 alloy at $759.4 \mathrm{MPa}$ in dry air and $729.5 \mathrm{MPa}$ in $3.5 \mathrm{wt} \%$ $\mathrm{NaCl}$ solution by slow strain rate test.

According RRA treatment, interrupted $\eta$ phases and wide PFZ can improve SCC resistance of the alloy. And reticular dislocations in the matrix during slow strain rate test can decrease the possibility of hydrogen crack and are conducive to improving SCC resistance of alloys.

Fractures of specimens after RRA treatment by slow strain rate test are dimple fracture in dry air and quasicleavage fracture in $3.5 \% \mathrm{NaCl}$ solution.

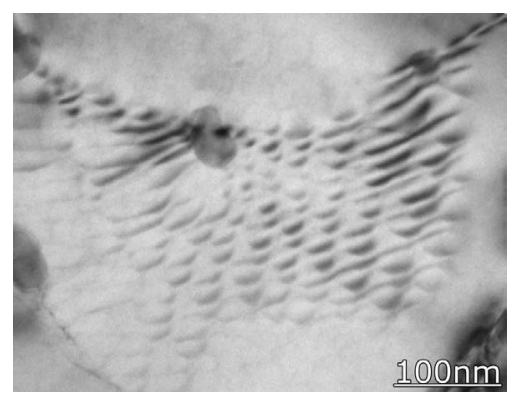

Figure 4. TEM images of deformation zone after RRA and slow strain rate test (reticular dislocations). 


\section{Acknowledgements}

This research was financially supported by the National Natural Science Foundation of China (51574167) and Program for Innovative Research Team in University of Liaoning Province (LT2015020).

\section{References}

[1] Marlaud, T., Deschamps, A., Bley, F., Lefebvrec, W. and Baroux, B. (2010) Influence of Alloy Composition and Heat Treatment on Precipitate Composition in Al-Zn-Mg-Cu Alloys. Acta Materialia, 58, 248-260. http://dx.doi.org/10.1016/j.actamat.2009.09.003

[2] Marlaud, T., Deschamps, A., Bley, F., Lefebvrec, W. andB aroux, B. (2010) Evolution of Precipitate Microstructures during the Retrogression and Re-Ageing Heat Treatment of an Al-Zn-Mg-Cu Alloy. Acta Materialia, 58, 4814-4826. http://dx.doi.org/10.1016/j.actamat.2010.05.017

[3] George, S.L. and Knutsen, R.D. (2012) Composition Segregation in Semi-Solid Metal Cast AA7075 Aluminium Alloy. Journal of Materials Science, 47, 4716-4725. http://dx.doi.org/10.1007/s10853-012-6340-3

[4] Ricker, R.E., Lee, E.U., Taylor, R., Lei, C., Pregger, B. and Lipnickas, E. (2013) Chloride Ion Activity and Susceptibility of Al Alloys 7075-T6 and 5083-H131 to Stress Corrosion Cracking. Metallurgical and Materials Transactions A, 44, 1353-1364. http://dx.doi.org/10.1007/s11661-012-1500-2

[5] Jeyakumar, M., Kumar, S. and Gupta, G.S. (2010) Microstructure and Properties of the Spray-Formed and Extruded 7075 Al Alloy. Materials and Manufacturing Processes, 25, 777-785. http://dx.doi.org/10.1080/10426910903447253

[6] Fang, J., Wong, P.C., Mitchell, K.A.R. and Foster, T. (1998) Observations Related to the Phosphating of Aluminium Alloy 7075-T6 Using a Spraying Technique. Journal of Materials Science, 33, 1541-1547. http://dx.doi.org/10.1023/A:1017507602553

[7] Ohnishi, T., Ibaraki, Y. and Ito, T. (1989) Improvement of Fracture Toughness in 7475 Aluminum Alloy by the RRA (Retrogression and Re-Aging) Process. Materials Transactions JIM, 30, 601-607. http://dx.doi.org/10.2320/matertrans1989.30.601

[8] Tsai, T.C., Chang, J.C. and Chuang, T.H. (1997) Stress Corrosion Cracking of Superplastically Formed 7475 Aluminum Alloy. Metallurgical and Materials Transactions A, 28, 2113-2121. http://dx.doi.org/10.1007/s11661-997-0168-5

[9] Ye, X., Ye, Y. and Tang, G. (2014) Effect of Electropulsing Treatment and Ultrasonic Striking Treatment on the Mechanical Properties and Microstructure of Biomedical Ti-6Al-4V Alloy. Journal of the Mechanical Behavior of Biomedical Materials, 40, 287-296. http://dx.doi.org/10.1016/j.jmbbm.2014.08.022

[10] Ye, X., Ye, Y. and Tang, G. (2014) Microhardness and Corrosion Behavior of Surface Gradient Oxide Coating on the Titanium Alloy Strips under High Energy Electro-Pulsing Treatment. Surface and Coatings Technology, 258, 467-484. http://dx.doi.org/10.1016/j.surfcoat.2014.08.052

[11] Cooper, K.R. and Kelly, R.G. (2007) Crack Tip Chemistry and Electrochemistry of Environmental Cracks in AA 7050. Corrosion Science, 49, 2636-2662. http://dx.doi.org/10.1016/j.corsci.2006.12.001

[12] Puiggaly, M., Zielinski, A., Olive, J.M., Renauld, E., Desjardins, D. and Cid, M. (1998) Effect of Microstructure on Stress Corrosion Cracking of an Al-Zn-Mg-Cu Alloy. Corrosion Science, 40, 805-819. http://dx.doi.org/10.1016/S0010-938X(98)00002-X

[13] Yue, T.M., Yan, L.J., Dong, C.F. and Chan, C.P. (2005) Stress Corrosion Cracking Behaviour of Laser Treated Aluminium Alloy 7075 Using a Slow Strain Rate Test. Materials Science and Technology, 21, 961-966. http://dx.doi.org/10.1179/174328405X47573

[14] Tanner, D.A. and Robinson, J.S. (2006) Residual Stress Magnitudes and Related Properties in Quenched Aluminium Alloys. Materials Science and Technology, 22, 77-85. http://dx.doi.org/10.1179/174328406X79414

[15] Arnold, E.M., Schubbe, J.J., Moran, P.J. and Bayles, R.A. (2012) Comparison of SCC Thresholds and Environmentally Assisted Cracking in 7050-T7451 Aluminum Plate. Journal of Materials Engineering and Performance, 21, 24802486. http://dx.doi.org/10.1007/s11665-012-0204-5

[16] Fooladfar, H., Hasnemi, B. and Younesi, M. (2010) The Effect of the Surface Treating and High-Temperature Aging on the Strength and SCC Susceptibility of 7075 Aluminum Alloy. Journal of Materials Engineering and Performance, 19, 852-859. http://dx.doi.org/10.1007/s11665-009-9562-z

[17] Silva, G., Rivolta, B., Gerosa, R. and Derudi, U. (2013) Study of the SCC Behavior of 7075 Aluminum Alloy after One-Step Aging at $163^{\circ} \mathrm{C}$. Journal of Materials Engineering and Performance, 22, 210-214. http://dx.doi.org/10.1007/s11665-012-0221-4

[18] Peng, G., Chen, K., Chen, S. and Fang, H. (2011) Influence of Repetitious-RRA Treatment on the Strength and SCC Resistance of Al-Zn-Mg-Cu Alloy. Materials Science and Engineering: A, 528, 4014-4018. 
http://dx.doi.org/10.1016/j.msea.2011.01.088

[19] Oliveira Jr., A.F., De Barros, M.C., Cardoso, K.R. and Travessa, D.N. (2004) The Effect of RRA on the Strength and SCC Resistance on AA7050 and AA7150 Aluminium Alloys. Materials Science and Engineering: A, 379, 321-326. http://dx.doi.org/10.1016/j.msea.2004.02.052

[20] Su, R.M., Qu, Y.D. and Li, R.D. (2014) Effect of Aging Treatments on the Mechanical and Corrosive Behaviors of Spray-Formed 7075 Alloy. Journal of Materials Engineering and Performance, 23, 3842-3848. http://dx.doi.org/10.1007/s11665-014-1186-2

[21] Su, R.M., Qu, Y.D., You, J.H. and Li, R.D. (2015) Study on Microstructure, Mechanical Properties and Corrosion Behavior of Spray Formed 7075 Alloy. Materials Today Communications, 4, 109-115. http://dx.doi.org/10.1016/j.mtcomm.2015.06.003

[22] Wang, F., Xiong, B., Zhang, Y., Zhu, B., Liu, H. and He, X. (2008) Effect of Heat Treatment on the Microstructure and Mechanical Properties of the Spray-Deposited Al-10.8Zn-2.8Mg-1.9Cu Alloy. Materials Science and Engineering: A, 486, 648-652. http://dx.doi.org/10.1016/j.msea.2007.09.049

[23] Cai, Y.H., Liang, R.G., Su, Z.P. and Zhang, J.S. (2011) Microstructure of Spray Formed Al-Zn-Mg-Cu Alloy with Mn Addition. Transactions of Nonferrous Metals Society of China, 21, 9-14. http://dx.doi.org/10.1016/S1003-6326(11)60671-7

[24] Bai, P., Hou, X., Zhang, X., Zhao, C. and Xing, Y. (2009) Microstructure and Mechanical Properties of a Large Billet of Spray Formed Al-Zn-Mg-Cu Alloy with High Zn Content. Materials Science and Engineering: A, 508, 23-27. http://dx.doi.org/10.1016/j.msea.2008.12.010

[25] Salamci, E. (2001) Ageing Behaviour of Spray Cast Al-Zn-Mg-Cu Alloys. Turkish Journal of Engineering and Environmental Science, 25, 681-686.

[26] Salamci, E. (2002) Mechanical Properties of Spray Cast 7XXX Series Aluminum Alloys. Turkish Journal of Engineering and Environmental Sciences, 26, 345-352.

[27] Sha, G. and Cerezo, A. (2004) Early-Stage Precipitation in Al-Zn-Mg-Cu Alloy (7050). Acta Materialia, 52, 45034516. http://dx.doi.org/10.1016/j.actamat.2004.06.025

[28] Jiang, H. and Faulkner, R.G. (1996) Modelling of Grain Boundary Segregation, Precipitation and Precipitate-Free Zones of High Strength Aluminium Alloys-I. The Model. Acta Materialia, 44, 1857-1864. http://dx.doi.org/10.1016/1359-6454(95)00317-7

[29] Jiang, H. and Faulkner, R.G. (1996) Modelling of Grain Boundary Segregation, Precipitation and Precipitate-Free Zones of High Strength Aluminium Alloys-II. Application of the Models. Acta Materialia, 44, 1865-1871. http://dx.doi.org/10.1016/1359-6454(95)00318-5

[30] Wei, R.P., Pao, P.S., Hart, R.G., Weir, T.W. and Simmons, G.W. (1980) Fracture Mechanics and Surface Chemistry Studies of Fatigue Crack Growth in an Aluminum Alloy. Metallurgical and Materials Transactions A, 11, 151-158.

[31] Chu, W.Y. and Thompson, A.W. (1992) Hydrogen Effects on Brittle Fracture of the Titanium Aluminide Alloy Ti24Al-11Nb. Metallurgical Transactions A, 23, 1299-1312. http://dx.doi.org/10.1007/BF02665062 